\title{
ESPECTROMETRIA DE MASSAS COM IONIZAÇÃO POR "ELECTROSPRAY": PROCESSOS QUÍMICOS ENVOLVIDOS NA FORMAÇÃO DE ÍONS DE SUBSTÂNCIAS ORGÂNICAS DE BAIXO PESO MOLECULAR
}

\section{Antônio Eduardo Miller Crotti}

Departamento de Química, Faculdade de Filosofia, Ciências e Letras de Ribeirão Preto, Universidade de São Paulo, Av. Bandeirantes, 3900, 14040-901 Ribeirão Preto-SP

Ricardo Vessecchi, João Luis Callegari Lopes e Norberto Peporine Lopes*

Faculdade de Ciências Farmacêuticas de Ribeirão Preto, Universidade de São Paulo, Av. do Café, s/n, 14040-903 Ribeirão Preto-SP

Recebido em 16/12/04; aceito em 1/7/05; publicado na web em 27/1/06

\begin{abstract}
ELECTROSPRAY IONIZATION MASS SPECTROMETRY: CHEMICAL PROCESSES INVOLVED IN THE ION FORMATION FROM LOW MOLECULAR WEIGHT ORGANIC COMPOUNDS. An overview of the current literature on the chemical processes involved in the ion formation from low molecular weight organic compounds by electrospray ionization mass spectrometry is given.
\end{abstract}

Keywords: electrospray ionization; mass spectrometry; organic compounds.

\section{INTRODUÇÃO}

Nos últimos anos, a espectrometria de massas com ionização por "electrospray" (IES-EM) tem se difundido às mais diversas áreas da ciência (Figura 1). A importância desta técnica reflete-se no número crescente de artigos publicados que a utilizam (Figura 2), seja para simples determinação do peso molecular e/ou quantificação de uma substância ou mesmo em estudos de determinação estrutural.

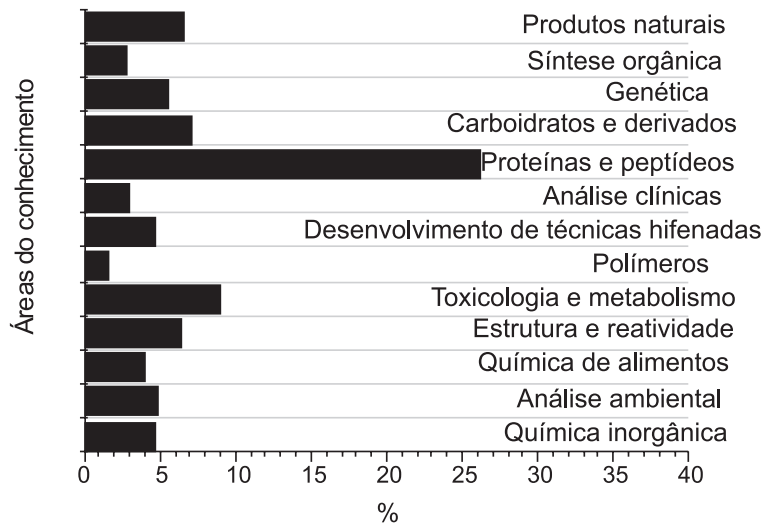

Figura 1. Utilização da espectrometria de massas em diferentes áreas do conhecimento. Todos os dados foram obtidos de pesquisa realizada em www.isiknowledge.com, no período de 1993 a 2004, considerando as 500 primeiras citações de cada ano. No gráfico aparecem apenas áreas que atingiram mais de $1 \%$

A crescente utilização da IES-EM pode ocasionar o uso equivocado de termos e regras associados à ionização por eletrons (IEEM). Considerando-se que alguns destes termos estão relacionados à natureza dos íons gerados, é necessário compreender não apenas o mecanismo de ionização, mas também os processos quí-

*e-mail: npelopes@fcfrp.usp.br

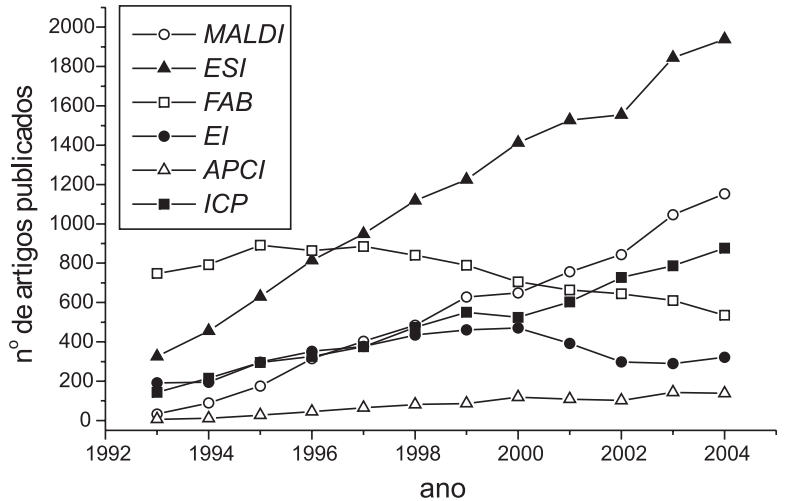

Figura 2. Número total de artigos publicados envolvendo as técnicas de ionização mais utilizadas. Baseado nos dados obtidos de pesquisa realizada em www.isiknowledge.com, no período de 1993 a 2004

micos envolvidos na formação e na estabilização das espécies observadas nos espectros de IES-EM.

Em trabalho recente, Moraes e Lago $^{1}$ descreveram a fonte de ionização por "electrospray" e o mecanismo de formação dos íons de moléculas inorgânicas na fase gasosa. Para estudos com moléculas orgânicas, os mesmos princípios são válidos e, portanto, não serão abordados detalhadamente neste texto. $\mathrm{O}$ que merece maior ênfase é o fato de que, para cada substância, os íons observados em seu espectro de massas estão relacionados às suas propriedades químicas: reações ácido-base, complexação com cátions ou ânions e/ou reações redox.

A falta de compreensão destas propriedades pode acarretar em dificuldades na interpretação dos espectros, principalmente para estudantes que estão em contato com a técnica pela primeira vez.

Nesse sentido, no presente artigo estão abordadas a influência das propriedades químicas de substâncias orgânicas de baixo peso molecular na formação dos íons na fonte "electrospray", as modificações no balanço entre os diferentes processos, bem como algumas terminologias comumente associadas aos íons resultantes. 


\section{TIPOS DE ÍONS GERADOS POR "ELECTROSPRAY"}

Durante a ionização por "electrospray", três tipos de íons podem ser gerados: íons moleculares, moléculas protonadas/desprotonadas (íons quasi-moleculares) e moléculas cationizadas ou anionizadas. A extensão com a qual cada um destes íons é formado pode ser compreendida em termos do balanço entre três processos essencialmente distintos, que ocorrem no interior do capilar: reações redox (oxidação/redução), que produzem íons moleculares $\left(\mathrm{M}^{+*}\right)$ ou $\left(\mathrm{M}^{-}{ }^{\bullet}\right.$ ); reações ácido/base (protonação/desprotonação), que resultam na formação de moléculas protonadas $\left([\mathrm{M}+\mathrm{H}]^{+}\right.$ou desprotonadas $[\mathrm{M}-\mathrm{H}]^{-}$) e, coordenação com cátions (geralmente os da família 1A) ou ânions (principalmente cloretos), que leva à formação de moléculas cationizadas $\left([\mathrm{M}+\mathrm{Na}]^{+},[\mathrm{M}+\mathrm{K}]^{+}\right.$, ou anionizadas $[\mathrm{M}+\mathrm{Cl}]^{-}$etc).

\section{Reações redox na fonte de ionização por "electrospray"}

Em relação aos processos eletroquímicos envolvidos, a fonte de ionização por "electrospray" pode ser considerada como uma célula eletrolítica à corrente controlada (CCE).

Conforme descrito por Kerbale ${ }^{2,3}$, o potencial elétrico aplicado no capilar metálico $(\mathrm{kV})$ promove a migração de cargas para a interface capilar/solução, formando uma dupla camada elétrica. Este processo resulta na formação de gotas com superfícies carregadas. A evaporação do solvente, devido à ação do gás nebulizador, diminui o tamanho destas gotas e, conseqüentemente, aumenta a repulsão eletrostática entre as cargas formais $\mathbf{q}$ em suas superfícies. A tensão superficial das gotas vai se tornando cada vez menor até ocorrer o fenômeno de "explosão coulômbica" das mesmas, que resulta na formação de gotas menores, com posterior liberação dos íons. Forma-se, assim, um "spray" de partículas carregadas ${ }^{4-6}$, ou seja, uma corrente eletrolítica.

A fonte de ionização por "electrospray" apresenta, portanto, os três constituintes básicos de uma célula eletrolítica: o eletrodo de trabalho (o capilar), onde o potencial é aplicado, o contra-eletrodo (o cone extrator e/ou "skimmer", dependendo do equipamento) e a fase eletrolítica ${ }^{7}$. A principal diferença em relação a uma célula eletrolítica é que, neste caso, a fase eletrolítica é gasosa e não líquida (Figura 3). Assim sendo, a natureza dos íons gerados por IES dependerá do comportamento das espécies da amostra em presença desta célula $^{8}$. No entanto, para que a fonte de ionização opere como célula eletrolítica, vários fatores devem ser considerados, tais como, velocidade de fluxo da solução no capilar, magnitude da corrente IES (I IES $)$ e potencial redox das espécies em solução ${ }^{8}$.

A velocidade de fluxo está diretamente ligada à organização da dupla camada elétrica (DCE) que se forma na interface capilar/ solução. Esta organização é fundamental para que ocorra a transferência de elétrons do capilar para a solução e a separação de cargas na superfície das gotas, que irão dar origem aos íons em fase gasosa. Quanto menor for o fluxo, maior será o tempo de residência das espécies neutras na interface capilar/solução e, conseqüentemente, as reações de oxidação do analito e de outras espécies contaminantes poderão ocorrer em maior extensão ${ }^{8-11}$.

A corrente IES ( $\mathrm{I}_{\mathrm{IES}}$ ) pode ser calculada pelo produto da velocidade com que as gotas são formadas e a média das cargas por gota ${ }^{8}$. Quando a magnitude desta corrente for de mesma ordem que a corrente faradaica $\left(\mathrm{I}_{\mathrm{F}}\right)$ e a diferença de potencial entre o capilar e o "skimmer" for maior ou igual que o potencial redox das espécies em solução, poderão ocorrer reações redox $^{8,9}$ (Equação 1).

$\mathrm{i}_{\mathrm{IES}}=\mathrm{i}_{\mathrm{F}}=\sum \mathrm{n}_{\mathrm{j}} \mathrm{A}_{\mathrm{j}} \mathrm{F} v$

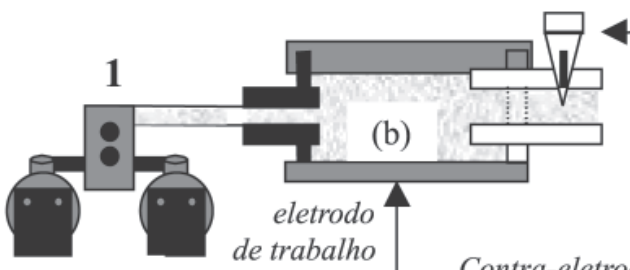

(a)

Contra-eletrodo

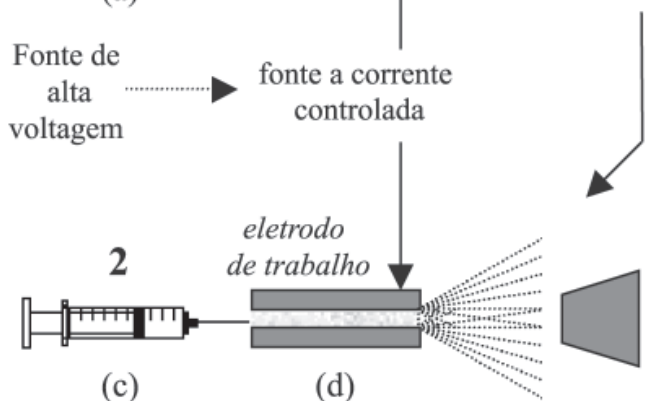

Figura 3. Analogia entre célula eletrolítica (1) e fonte de ionização linear por "electrospray" (2). (a) bomba injetora de fluxo; (b) célula-fluxo; (c) bomba de infusão; (d) capilar IES e (e) região entre cone extrator e "skimmer". O analito é inserido através de (c), onde sofre a influência do potencial aplicado ao capilar (d). Em células convencionais, o contra-eletrodo pode ser um fio de $\mathrm{Pt}$

onde, $\mathrm{n}$ - número de elétrons, A - área do eletrodo, F - constante de Faraday e $v$ - velocidade.

Nestas condições, a fonte IES poderá atuar como uma CCE, oxidando ou reduzindo as espécies mencionadas, gerando íons moleculares $\left(\mathrm{M}^{+*} \mathrm{ou} \mathrm{M}^{-}{ }^{\bullet}\right)$. As espécies com menor potencial redox, obviamente, reagirão preferencialmente ${ }^{7,8}$.

De maneira geral, a facilidade com que uma molécula pode perder um elétron, ou seja, oxidar-se, depende da energia dos orbitais moleculares ocupados (HOMO), que pode ser estimada através de cálculos teóricos e de medidas experimentais do potencial de oxidação da substância em solução $\left(\mathrm{E}_{\mathrm{ox}}\right)$ ou de sua energia de ionização (EI) em fase gasosa. Embora exista, para uma ampla faixa de compostos, uma correlação entre essas duas grandezas $\left(\mathrm{E}_{\text {ox }}\right.$ e $\left.\mathrm{EI}\right)$, os valores de $\mathrm{E}_{\mathrm{ox}}$ são afetados pela solvatação e, por isso, devem ser medidos nas mesmas condições experimentais, principalmente quanto ao sistema solvente ${ }^{2,3,12}$.

Van Berkel e colaboradores testaram e parametrizaram o funcionamento da fonte IES como CCE e comprovaram a formação de espécies oxidadas/reduzidas através da utilização de um detector UV/visível ${ }^{2,3,8-15}$. Seus trabalhos demonstraram que em substâncias que apresentam sistemas $\pi$ conjugados, e que não apresentam funções básicas (principalmente aminas e funções carboniladas), a redução e/ou oxidação ocorrem mais facilmente que a protonação das mesmas. Para substâncias policíclicas aromáticas cujo potencial de oxidação é inferior a 1,0 V (vs ECS), a formação de espécies radicalares foi facilmente observada ${ }^{12}$. Nestes casos, a presença de íons moleculares $\left(\mathrm{M}^{+*}\right)$ foi predominante nos espectros de massas, enquanto que a molécula protonada $\left([\mathrm{M}+\mathrm{H}]^{+}\right)$aparece com baixa abundância relativa.

Estudos recentes, realizados com polienos, relataram a presença em baixa abundância de íons radicalares $\left(\mathrm{M}^{+*}\right)$ no espectro de IES-EM de retinóides (Figura 4), que apresentam um extenso sistema $\pi$ conjugado em suas estruturas ${ }^{16}$. No caso do $\beta$ caroteno, que apresenta dois valores potenciais de oxidação muito próximos ${ }^{17}$, espécies duplamente carregadas também foram descritas, formadas a partir da perda de 2 elétrons ${ }^{17}$. 

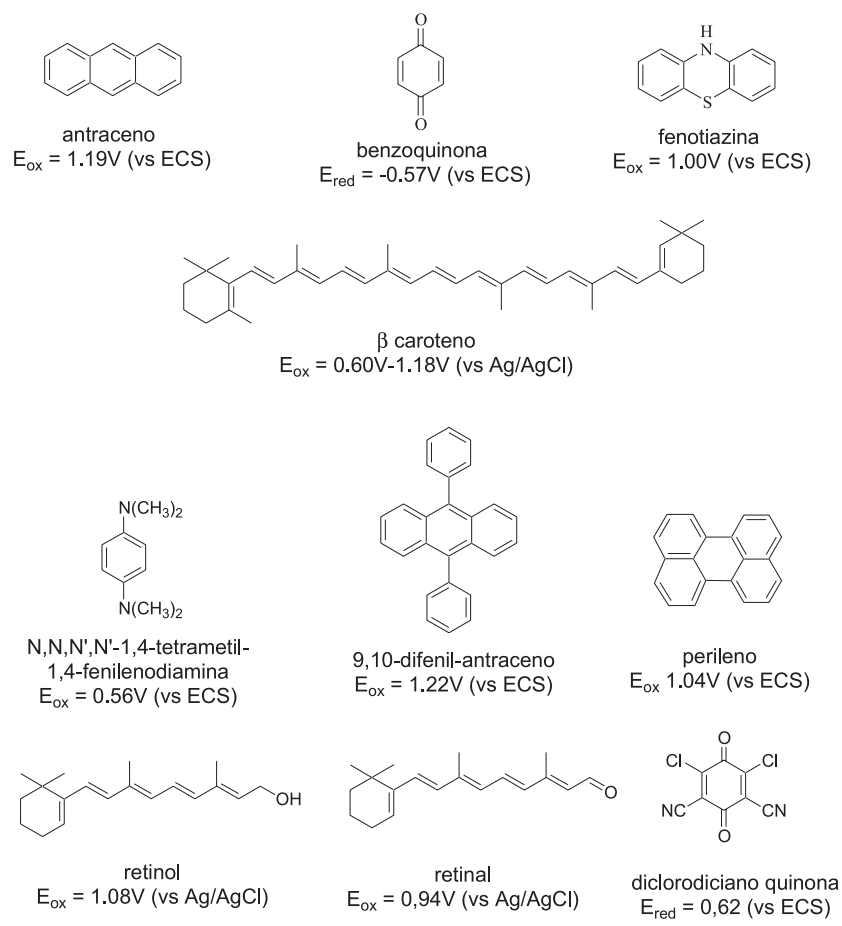

Figura 4. Algumas moléculas orgânicas (e seus respectivos potenciais redox) que produzem íons moleculares em seus espectros de IES-EM

\section{Reações ácido-base versus coordenação com metais}

A ionização da grande maioria das substâncias orgânicas que apresentam potenciais redox não muito baixos (considerando sua oxidação) e/ou que não apresentem sistemas com alta densidade eletrônica (sistemas $\pi$ policonjugados) geralmente ocorre através de reações ácido-base e/ou coordenação com íons metálicos, principalmente $\mathrm{Na}^{+} \mathrm{e}$ $\mathrm{K}^{+}$. Portanto, a maioria dos íons gerados por IES-EM são moléculas protonadas $\left([\mathrm{M}+\mathrm{H}]^{+}\right.$ou desprotonadas $\left.[\mathrm{M}-\mathrm{H}]^{-}\right)$e/ou cationizadas $\left([\mathrm{M}+\mathrm{Na}]^{+},[\mathrm{M}+\mathrm{K}]^{+},\left[\mathrm{M}+\mathrm{NH}_{4}\right]^{+} \text {ou anionizadas }[\mathrm{M}+\mathrm{Cl}]^{-}\right)^{4}$.

Embora a protonação e a desprotonação de uma substância sejam processos que ocorrem simultaneamente dentro do capilar, a extensão dos mesmos depende, dentre outros parâmetros, da estrutura da substância e do solvente. Substâncias que apresentam grupamentos básicos, principalmente aminas, amidas e ésteres, normalmente são analisadas no modo positivo, dada a relativa facilidade com que as mesmas são protonadas. Por outro lado, substâncias contendo funções ácidas, tais como ácidos carboxílicos e fenóis, são mais facilmente desprotonadas e, conseqüentemente, são analisadas no modo negativo ${ }^{4,18}$.

A natureza do solvente utilizado e o pH são igualmente importantes na geração de íons positivos e negativos. Íons positivos são geralmente analisados empregando-se soluções da amostra em metanol e com baixos valores de $\mathrm{pH}$. Íons negativos, por sua vez, são produzidos em maior proporção a partir de soluções em clorofórmio com altos valores de $\mathrm{pH}$.

É importante ressaltar que, embora as reações de protonação e de desprotonação ocorram inicialmente em solução, a identidade dos íons gasosos é função da afinidade protônica (para a protonação) e da acidez (para a desprotonação) da substância em fase gasosa. Estes parâmetros podem ser estimados experimentalmente ou através de cálculos teóricos e são essenciais para entendimento da reatividade de uma substância em fase gasosa ${ }^{19,20}$. Conceitualmente, a basicidade de $\mathrm{B}^{\mathrm{n}-1}$ é o valor negativo da energia livre para a reação (Equação 2a), enquanto que a afinidade protônica é o valor negativo da variação de entalpia padrão da mesma espécie na mesma reação, conforme a Segunda Lei da Termodinâmica ${ }^{19-21}$ (Equação 2b).

$\mathrm{H}_{(\mathrm{g})}^{+}+\mathrm{B}_{(\mathrm{g})}^{\mathrm{n}-1} \rightleftharpoons \mathrm{HB}_{(\mathrm{g})}^{\mathrm{n}}$

$\Delta \mathrm{G}^{\circ}=\Delta \mathrm{H}^{\circ}-\mathrm{T} \Delta \mathrm{S}^{\circ}$

Embora a formação de moléculas anionizadas com íons cloreto $([\mathrm{M}+\mathrm{Cl}]$ ), no modo negativo, tenha sido observada em alguns casos, a coordenação com íons metálicos (principalmente os da família 1A) é descrita com mais frequiência na literatura. Esta coordenação depende do número e da disposição espacial de átomos contendo pares de elétrons não ligantes, podendo resultar no íon mais intenso no espectro de IES-EM de substâncias como a monensina, que pode assumir uma conformação quasi-cíclica, na qual o sódio coordena-se com os oxigênios dos anéis tetraidrofurânicos (Figura 5) 22 .

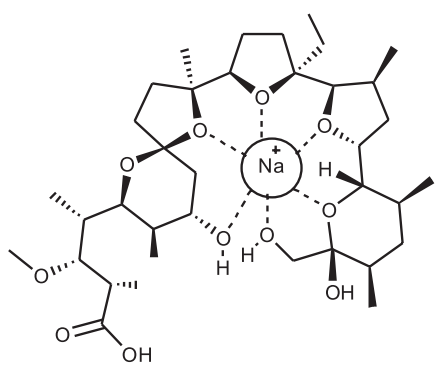

Figura 5. Conformação quasi-cíclica da monensina sodiada. Os pares de elétrons (não ligantes) dos átomos de oxigênio são responsáveis pela interação com o íon sódio, o qual se encontra no interior da cavidade conformacional da monensina, estabilizando o aduto formado

Para estudo de substâncias em que a coordenação com metais ocorre em maior extensão que a protonação, várias metodologias vêm sendo desenvolvidas para favorecer a formação da molécula protonada $\left([\mathrm{M}+\mathrm{H}]^{+}\right)$, que é importante para estudos de elucidação estrutural através da técnica EM/EM. Estas metodologias baseiam-se na alteração de alguns parâmetros experimentais ( $\mathrm{pH}$ e potencial do cone extrator) e na adição de substâncias que competem pelos íons metálicos.

$\mathrm{O}$ pH do solvente é um dos parâmetros experimentais determinantes da extensão com a qual ocorrem as reações de protonação e coordenação. Soluções cujos valores de $\mathrm{pH}$ são baixos tendem a favorecer a protonação sobre a coordenação e, conseqüentemente, aumentam a intensidade de íons protonados no espectro de IESEM. Esta tendência também é observada com o aumento do $\mathrm{pH}$ que, por sua vez, favorece as reações de desprotonação em moléculas de caráter mais ácido ${ }^{23}$.

Entretanto, dependendo da estrutura da substância, a coordenação com metais alcalinos pode ser o principal processo de geração de íons, mesmo em soluções de baixos valores de $\mathrm{pH}^{22-24}$.

\section{Efeito do potencial do cone de amostragem}

Uma das maneiras utilizadas para alterar a relação entre a molécuta protonada e a cationizada com sódio $[\mathrm{M}+\mathrm{Na}]^{+}$, em um mesmo $\mathrm{pH}$, é o aumento da voltagem do cone de amostragem (Figura 6). Um aumento na diferença entre os potenciais do cone de amostragem de íons e o cone extrator e/ou "skimmer" resulta na aceleração dos íons extraídos e, conseqüentemente, no aumento da energia da colisão dos mesmos com as moléculas de gás residual na região de pressão intermediária da fonte de ionização ${ }^{25}$ (Figura 6). Essa aceleração pode levar a uma maior dissociação das molé- 


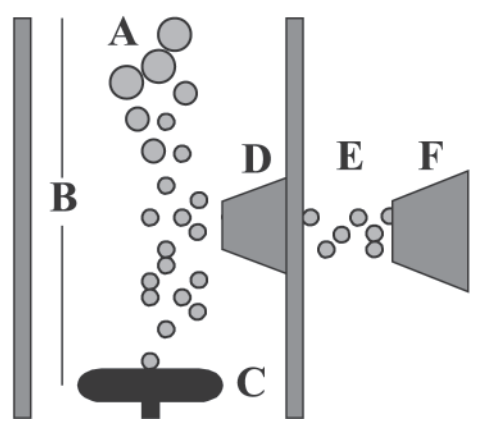

Figura 6. Esquema demonstrando a região entre o cone extrator e o prato defletor. (A) formação das gotas saindo do capilar; $(\boldsymbol{B})$ região a pressão atmosférica; $(\boldsymbol{C})$ defletor; $(\boldsymbol{D})$ cone de amostragem; $(\boldsymbol{E})$ região de pressão intermediária; $(\boldsymbol{F})$ região do cone extrator e do "skimmer". As gotas ao saírem do capilar migram em direção ao cone extrator devido ao potencial aplicado ao mesmo, podendo se chocar contra o defletor (barreira física). Após a passagem pelo cone extrator os íons são guiados ao quadrupolo, onde serão analisados

culas cationizadas ou das moléculas protonadas ${ }^{26}$, dependendo da substância. Esta dissociação, conhecida como dissociação induzida na fonte de ionização ou, simplesmente, dissociação na fonte ("insource dissociation") ${ }^{18}$, pode ser utilizada para obtenção de informações estruturais de substâncias puras e/ou previamente separadas por CLAE/EM ${ }^{25,26}$. Com relação as informações sobre os fragmentos observados nos espectros de dissociação, um dos maiores problemas é a transferência de carga do fragmento carregado para outro fragmento neutro, o qual pode ser proveniente da molécula ou ser ainda um produto neutro qualquer da matriz. Um estudo recente sobre a dissociação na fonte do ácido lasalocido mostrou claramente a transferência de carga entre o fragmento carregado e a porção neutra da molécula, provando esse balanço ${ }^{28}$ (Figura 7).

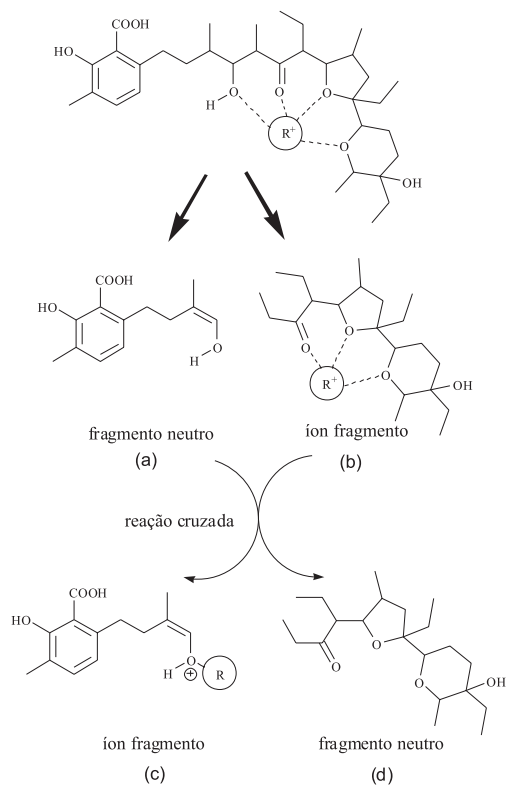

Figura 7. Esquema da dissociação na fonte do ácido lasalocido. Inicialmente, tem-se a molécula protonada ou cationizada com sódio. Após serem aceleradas no cone, originam duas espécies distintas ( $b$ e c) observadas no espectro IES-EM. A primeira espécie (b) está relacionada com o produto de fragmentação EM-EM sendo, portanto, um fragmento esperado. A segunda espécie (c) é produto da reação cruzada de transferência de carga entre um ín neutro e o fragmento esperado, levando a um íon que não aparece no espectro de $E M / E M(d)$
Uma das desvantagens desta técnica de dissociação deve-se à ocorrência de reações "cruzadas" (principalmente adição seguida de eliminação e dimerização) entre dois íons fragmentos, cujos íons produtos podem ser confundidos com as moléculas protonadas ${ }^{26}$. Um exemplo é o aumento na intensidade do íon em $\mathrm{m} / z, 671$ no espectro de IES-EM da monensina A com o aumento da voltagem do cone de amostragem, indicando um possível aumento no número de moléculas protonadas da monensina $\mathrm{A}^{23}$. A análise por espectrometria de massas de alta resolução revelou que este íon era, na realidade, produto de adição de água, seguida de uma reação de eliminação, resultando em uma grande modificação da capacidade de coordenar sódio devido à formação de um alceno na cadeia $^{22}$ (Figura 8). Portanto, o uso deste recurso deve ser cuidadosamente acompanhado para evitar interpretações errôneas.
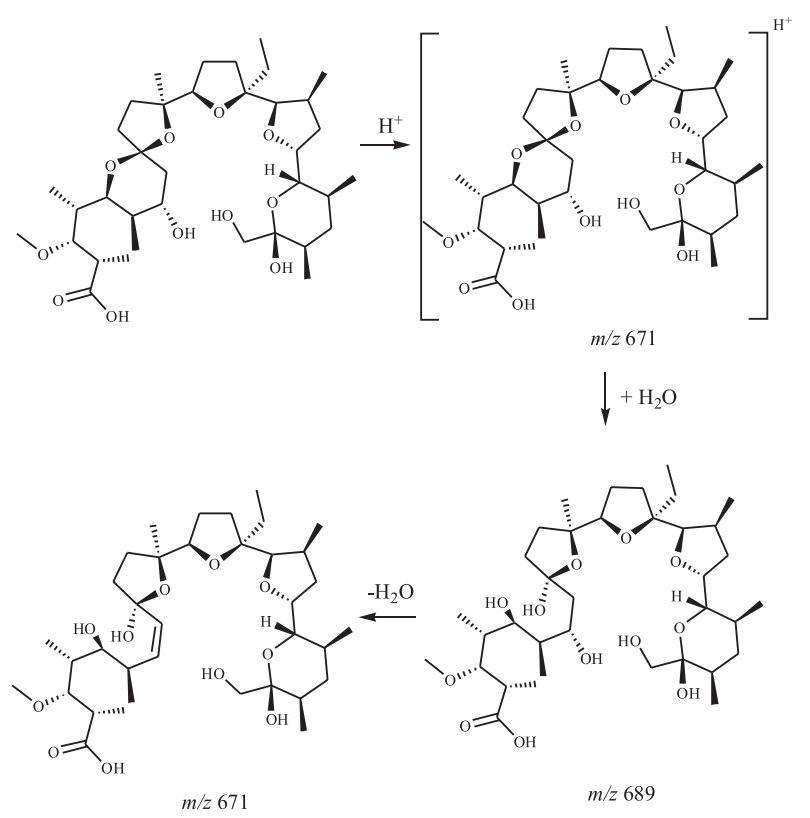

Figura 8. Esquema da formação da monensina protonada (m/z 671), aduto com água (m/z 689) e formação do alceno $(\mathrm{m} / \mathrm{z} 671)$

\section{Adição de competidores}

Uma outra metodologia que pode ser utilizada para aumentar a intensidade da molécula protonada no espectro de IES-EM é a adição de substâncias que competem pelos metais que normalmente formam as moléculas cationizadas $\left(\mathrm{Na}^{+} \mathrm{e} \mathrm{K}^{+}\right)$.

Os primeiros trabalhos científicos empregaram éteres de coroa como competidores para seqüestrar possíveis traços de metais presentes nas soluções analisadas por IES-EM ${ }^{29,30}$. O fenômeno de complexação destas moléculas ocorre não apenas para metais alcalinos, como também para metais de transição ${ }^{29}$, como por ex.,

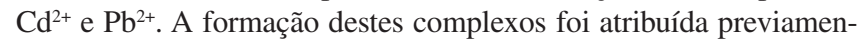
te à cavidade do éter, a qual determina a estequiometria do complexo em solução ${ }^{29}$.

Atualmente, o emprego dos éteres de coroa não se limita à coordenação com cátions metálicos, mas também no estudo das constantes de estabilidade ${ }^{31}$ e de formação ${ }^{32}$ destes complexos. Kempen ${ }^{32}$, estudando a coordenação de metais alcalinos e alcalinos terrosos por IES-EM, descreveu a formação de complexos de tioéteres de coroa com metais alcalinos e metais de transição. A complexação com metais alcalinos terrosos, no entanto, não foi observada.

Williams ${ }^{33}$ utilizando macrociclos contendo heteroátomos $(\mathrm{N}$, O) confirmou a dependência entre cavidade, número de átomos e 
presença de substituintes na complexação de metais como ouro, prata, cobre e ferro, entre outros. Os resultados obtidos demonstraram que a presença de heteroátomos e substituintes aromáticos na estrutura macrocíclica aumentavam seu poder seqüestrante para $\mathrm{Ag}^{+}$em soluções aquosas.

Outro problema enfrentado nas análises por IES-EM deve-se ao fato de algumas moléculas de solvente complexarem os metais presentes na solução, como é o caso do $\mathrm{Ni}^{2+}$ em acetonitrila, onde os agentes seqüestrantes utilizados para minimizar esta complexação são poliaminas pentadentadas ${ }^{34}$. Devido a este fato, estudos de estabilidade e labilidade de ambos complexos formados (metal:solvente ou metal:agente quelante) devem ser levados em consideração ${ }^{34}$.

Um dos problemas que limitam o uso de competidores do tipo éter de coroa e seus derivados é a quantidade necessária para deslocar o equilíbrio da formação da molécula cationizada para a molécula protonada. Contudo, a maior desvantagem deve-se ao fato destes macrociclos aderirem ao cone de amostragem e também ao quadrupolo, podendo interferir em análises futuras ${ }^{35}$. A utilização de cloreto de rutênio(III) possibilitou a obtenção de moléculas protonadas de substâncias com alto poder coordenante, como dimetil- $\beta$-ciclodextrina e valinomicina (Figura 9). Estudos prévios com estas substâncias descreviam apenas a presença de moléculas cationizadas com sódio em seus espectros IES-EM ${ }^{24}$.

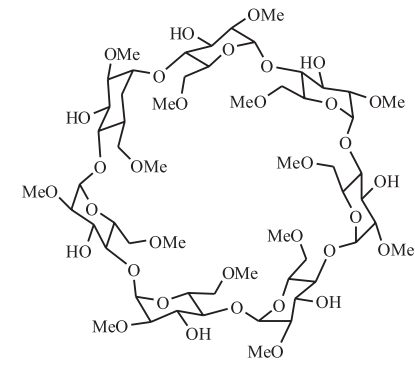

dimetil- $\beta$-ciclodextrina

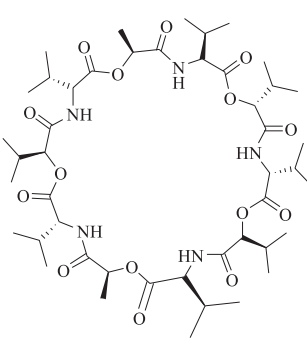

valinomicina
Figura 9. Moléculas de alto poder coordenante estudadas por IES-EM, para as quais as moléculas protonadas foram observadas após adição de cloreto de rutênio (III) à solução

Além de sequestrar os íons metálicos presentes na solução, o cloreto de rutênio(III) pode competir com o metal presente na cavidade da molécula estudada, abstraindo-o, de maneira que a molécula poderá ser protonada e, portanto, a molécula protonada ser observada no espectro de IES-EM correspondente ${ }^{24}$. A maior vantagem da utilização de $\mathrm{RuCl}_{3}$ está relacionada à estrutura formada entre as unidades de cloreto de rutênio(III) e os átomos de metais alcalinos (Figura 10), bem como à facililidade com que pode ser removido do equipamento, uma vez que é utilizado em menor quantidade que os éteres de coroa e seus derivados.

A natureza da competição eficiente do cloreto de rutênio(III) por cátions de metais alcalinos ainda é desconhecida ${ }^{35}$. Acredita-se que ânions do tipo $\mathrm{RuCl}_{4}$ - e $\mathrm{RuCl}_{5}^{2-}$, que são formados em solução aquo$\mathrm{sa}^{35}$, possam originar complexos neutros insolúveis com metais alcalinos que, sob as condições da fonte de ionização por "electrospray" (modo positivo ou negativo), não são detectados. Análises desses complexos insolúveis por MALDI-ToF demonstraram a presença de $\left[\mathrm{RuCl}_{4} \mathrm{Na}\right]$ e $\left[\mathrm{RuCl}_{5} \mathrm{Na}_{2}\right]^{24}$, comprovando as estruturas dos mesmos.

\section{CONCLUSÕES}

A técnica IES-EM envolve a formação de diferentes tipos de

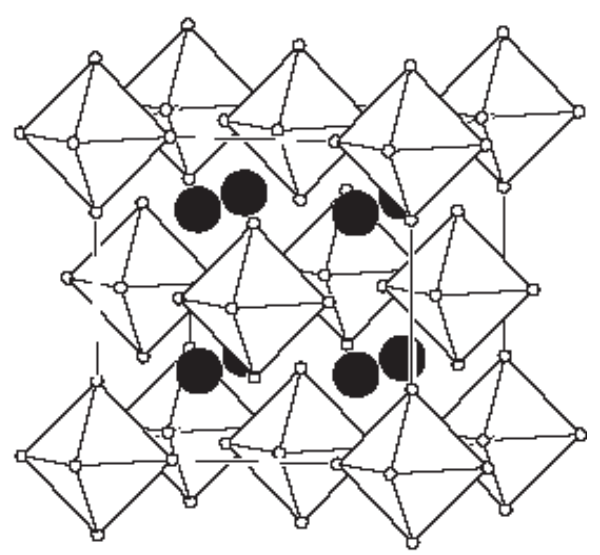

Figura 10. Esquema ilustrativo demonstrando a captura dos cátions $\mathrm{Na}^{+}$ através da estrutura do cloreto de rutênio (III)

íons (moleculares, molécula protonada, molécula cationizada). Além da presença de extensos sistemas $\pi$ conjugados, a extensão com que as reações redox ocorrem (e, conseqüentemente, a intensidade dos íons moleculares no espectro de massas) é também dependente de uma combinação adequada de parâmetros experimentais. No caso das reações ácido-base de Brönsted-Lowry e coordenação com íons metálicos, que resultam na formação de moléculas protonadas e moléculas cationizadas, respectivamente, é possível controlar a extensão com que cada um desses processos ocorre no interior do capilar, através do ajuste de alguns parâmetros experimentais ( $\mathrm{pH}$, voltagem do cone de amostragem), bem como pela adição de competidores à solução da amostra. A adição de competidores é, atualmente, uma das metodologias mais promissoras para obtenção de moléculas protonadas de substâncias com alta capacidade de coordenação. O conhecimento destes processos químicos, alguns dos quais foram apresentados neste artigo, podem auxiliar na análise e interpretação do espectro de massas obtido por IESEM e ajudar os estudantes de graduação e pós-graduação a se familiarizarem um pouco mais com a técnica.

\section{REFERÊNCIAS}

1. Moraes, M. C. B.; Lago, C. L.; Quim. Nova 2003, 26, 556.

2. Jayaweera, P.; Blades, A. T.; Ikonomou, M. G.; Kebarle, P.; J. Am. Chem. Soc. 1990, 112, 2452.

3. Ikonomou, M. G.; Blades, A. T.; Kebarle, P.; Anal. Chem. 1991, 63, 1989.

4. Cole, R. B., ed.; Electrospray Mass Spectrometry: fundamentals, instrumentation \& applications; John Wiley \& Sons: New York, 1997.

5. Fenn, J. B.; Int. J. Mass Spectrom. 2000, 200, 459.

6. Yamashita, M.; Fenn, J. B.; J. Phys. Chem. 1984, 88, 4451.

7. Bard, A. J.; Falkner, L. R.; Electrochemical Methods-Fundamentals and Applications, John Wiley \& Sons: New York, 1980.

8. van Berkel, G. J.; Zhou, F.; Anal. Chem. 1995, 67, 2916.

9. De La Mora, J. F.; van Berkel, G. J.; Enke, C. G.; Cole, R. B.; MartinezSanchez, M.; Fenn, J. B.; J. Mass Spectrom. 2000, 35, 939.

10. van Berkel, G. J.; J. Mass Spectrom. 2000, 35, 773.

11. Xu, X.; Nolan, S. P.; Cole, R. B.; Anal. Chem. 1994, 66, 119.

12. van Berkel, G. J.; Zhou, F.; Anal. Chem. 1995, 67, 3958.

13. Kertesz, V.; van Berkel, G. J.; J. Mass Spectrom. 2001, 36, 204.

14. van Berkel, G. J.; Mcluckey, S. A.; Glish, G. L.; Anal. Chem. 1992, 64, 1586.

15. van Berkel, G. J.; Giles, G. E.; Bullock, J. S.; Gray, L. J.; Anal. Chem. 1999, 71, 5288 .

16. Guaratini, T.; Vessecchi, R. L.; Lavarda, F. C.; Maia-Campos, P. M. B. G.; Naal, Z.; Gates, P. J.; Lopes, N. P.; Analyst 2004, 129, 1223.

17. Dezhong, L.; Gao, Y.; Kispert, L. W.; J. Electroanal. Chem. 2000, 488, 140 .

18. Vestal, M. L.; Chem. Rev. 2001, 101, 361.

19. Gal, J. F.; Maria, P. C.; Raczynska, E. D.; J. Mass Spectrom. 2001, 36, 699.

20. Meot-Ner, M.; Int. J. Mass Spectrom. 2003, 227, 525. 
21. Deakyne, C. A.; Int. J. Mass Spectrom. 2000, 196, 215.

22. Lopes, N. P.; Stark, C. B. W.; Gates, P. J.; Staunton, J.; Analyst 2002, 127, 503.

23. Lopes, N. P.; Stark, C. B. W.; Hong, H.; Gates, P. J.; Staunton, J.; Analyst 2001, 126, 1630 .

24. Stark, C. B. W.; Lopes, N. P.; Fonseca, T.; Gates, P. J.; Chem. Commun. 2003, 21, 2732 .

25. Niessen, W. M. A.; Analusis 2000, 28, 885

26. Adejare, A.; Brown, P. W.; Anal. Chem. 1997, 69, 1525.

27. Solomons, G.; Organic Chemistry, Wiley, John \& Sons, Inc., 1995, p.1328.

28. Lopes, N. P.; Gates, P. J.; Wilkins, J. P. G.; Staunton, J.; Analyst 2002, 127, 1224.
29. Colton, R.; Mitchell, S.; Traeger, J. C.; Inorg. Chim. Acta 1995, $231,87$.

30. Shou, W. Z.; Browner, R. F.; Anal. Chem. 1999, 71, 3365.

31. Young, D. S.; Hung, H. Y.; Liu, L. K.; Rapid Commun. Mass Spectrom. 1997, 11, 769

32. Kempen, R. C.; Brodbelt, J. S.; Anal. Chem. 2001, 73, 384.

33. Williams S. M.; Brodbelt, J. S.; Huang, Z. L.; Lai, H. G.; Marchand, A. P.; Analyst 2003, 128, 1352.

34. Combariza, M. Y.; Vachet, R. W.; J. Am. Soc. Mass Spectrom. 2004, 15 , 1128.

35. Durrant, P. J.; Durrant, B.; Introduction to Advanced Inorganic Chemistry, Longman: London, 1972. 